\title{
Optimization of Threshold Ranges for Rapid Flood Inundation Mapping by Evaluating Backscatter Profiles of High Incidence Angle SAR Images
}

\author{
Panchagnula Manjusree*, L. Prasanna Kumar, Chandra Mohan Bhatt, Goru Srinivasa Rao, and \\ Veerubhotla Bhanumurthy
}

Disaster Management Support Group, Remote Sensing Applications Area, National Remote Sensing Centre, Indian Space Research Organization (ISRO), Balanagar, Hyderabad 500 625, India

\begin{abstract}
Rapid satellite-based flood inundation mapping and delivery of flood inundation maps during a flood event can provide crucial information for planners and decision makers to prioritize relief and rescue operations. The present study is undertaken to optimize the threshold ranges for the classification of flood water in Synthetic Aperture Radar (SAR) images (of $20^{\circ}$ to $49^{\circ}$ incidence angles) for quick flood inundation mapping and response during flood disasters. This is done through assessing the signature of flood water in Horizontal transmit and Horizontal received $(\mathrm{HH})$, Horizontal transmit and Vertical received (HV), Vertical transmit and Horizontal received $(\mathrm{VH})$, and Vertical transmit and Vertical received (VV) polarization radar data. The mean backscattering signature profiles of various water bodies were analyzed to discriminate flood water from other water bodies. The study shows that there is better demarcation of land-water surface in $\mathrm{HH}$ polarization. VV polarization has the potential to identify partially submerged features, which can be useful in flood damage assessments. The backscatter of flood water in $\mathrm{HV}$ and $\mathrm{VH}$ is the same and both $\mathrm{HV}$ and $\mathrm{VH}$ polarizations are adequate for the mapping of flood water. At near range to far range, -8 to $-12 \mathrm{~dB},-15$ to $-24 \mathrm{~dB}$, and -6 to $-15 \mathrm{~dB}$ can be used as optimum ranges for the classification of flood water in $\mathrm{HH}, \mathrm{HV}$, and VV polarizations. These optimum threshold ranges can be applied to the automation of flood mapping using SAR images in near-real time, where much time was often spent on finding the thresholds in order to produce flood inundation maps in a short time from the onset of flood disasters and deliver such maps to the concerned agencies.
\end{abstract}

Keywords flood, microwave, radar backscatter, synthetic aperture radar, threshold and polarization

\section{Introduction}

Floods are one of the most frequent and widespread natural hazards of the world. Flood inundation maps that provide an overview of flooding situation, assess damages, and facilitate improving crisis management and response activities are

\footnotetext{
* Corresponding author. E-mail: pmanjusree@yahoo.com
}

needed as quickly as possible when a flood has occurred. Identification of the areas affected by flood waters is a challenging task under unfavorable weather conditions and when communication systems have collapsed or transportation systems are damaged. Satellite-based flood inundation maps can be a very important input for assessing the progression of flood waters and the severity of the flood situation. Unlike optical (visible/infrared) sensors, Synthetic Aperture Radar (SAR) sensors, because of their capability to operate during daytime and night time and in almost all weather conditions, have emerged as one of the most important tools for providing reliable and near-real time information on flood disasters (Smith 1997).

Radar sensors are capable of precisely measuring the amount of returned energy, that is, backscatter, and can accurately delineate the terrain regardless of the time and weather (Campbell 2002). The potential of the SAR data for flood detection and mapping has been demonstrated by several previous investigations (for example, Horritt, Mason, and Luckman 2001). Mapping of water surface using SAR is possible because the SAR backscatter from water is very low since the water surface is smooth (Di Baldassarre et al. 2001). As a result, flooded areas appear as dark tones due to the low backscattering response whereas land surface appear as bright tones because the rough soil surface and vegetation produce diffused reflection resulting in a strong backscatter. The variation in radar backscatter from any feature on the ground may be a result of incident angle, acquisition date, look direction, moisture on the surface, or the physical composition of the feature itself. Similarly, the backscatter of water bodies behaves differently depending on parameters such as incidence angle, wavelength, and polarization. Incidence angle has been proved to have significant effects on SAR backscatters from different ground surfaces (Ulaby, Moore, and Fung 1986).

India is one of the most flood-prone countries in the world. Twenty-three of the thirty-five states and union territories in the country are subject to floods and forty million ha of land, roughly one-eighth of the country's geographical area, is prone to floods. Floods occur in almost all rivers basins in 
India. The main causes of floods are heavy rainfall, inadequate capacity of rivers to carry the high flood discharge, and inadequate drainage to carry away the rainwater quickly to streams/rivers. Microwave data is being extensively utilized for flood inundation mapping to assist disaster managers in conducting relief and rescue operations quickly and effectively. However, finding an optimal threshold to classify the images takes a large amount of valuable time, which in turn delays the generation of flood inundation maps. Therefore, the present study aims to optimize the threshold ranges for the classification of flood water in high incidence SAR images $\left(20^{\circ}\right.$ to $\left.49^{\circ}\right)$ for quick flood inundation mapping.

\section{Study Area}

The study area is part of the Kosi subbasin, within the Darbhanga District of Bihar State in India. It lies between $26^{\circ} 00^{\prime} 09^{\prime \prime}$ to $26^{\circ} 10^{\prime} 07^{\prime \prime} \mathrm{N}$ latitude and $85^{\circ} 48^{\prime} 24^{\prime \prime}$ to $85^{\circ} 55^{\prime} 37^{\prime \prime} \mathrm{E}$ longitude (Figure 1). The major rivers traversing through the study area are the Lakhonidi and Baghmati Rivers. The area is part of the North Bihar alluvial plains and consists of fluvial features like oxbow lake, palaeochannels, and meander streams. This part of the area witnesses severe flooding every year, especially the interlocked area between Lakhonidi River and Baghmati River, causing severe damage to infrastructure and crops. Most of the rainfall in the basin (80 to 90 percent) is received during mid-June to October. The monthly monsoon rainfall in the study area is about $1057 \mathrm{~mm}$. In 2011, heavy rainfall occurred during September to October. The water level of Lakhonidi River in the study area crossed the danger level $(45.72 \mathrm{~m})$ and reached $48.9 \mathrm{~m}$ on 29 September 2011, and remained above danger level for two weeks. This has caused severe damage to crops, road network, and properties.

\section{Satellite Data Used}

In the present study C-band (5.3 GHz) RADARSAT-2 SAR Fine beam (FQ 31) Quad polarization (HH, HV, VH, VV) data on 15 October 2011 were used for the analysis. Details of all satellite data used in this study are shown in Table 1. Using the fine beam SAR data, mean backscatter profiles were studied for different water bodies and optimum threshold ranges were finalized. The optimum threshold ranges derived from the analysis were validated using RADARSAT2 ScanSAR data of 19 July and 22 August 2011 (Table 1). High resolution digital camera (DC) image with a spatial resolution of $0.50 \mathrm{~m}$ was used for the validation of submerged features. Further, Resourcesat-1 IRS-P6 LISS-III optical data were taken as reference data for the validation of the classification and interpretations. Due to the non-availability of the optical data on 15 October, LISS-III image of 12 October 2011 was used for this purpose. The flood inundated area obtained using RADARSAT data is also compared with flood inundation derived from LISS-III data of 12 October (Table 1).

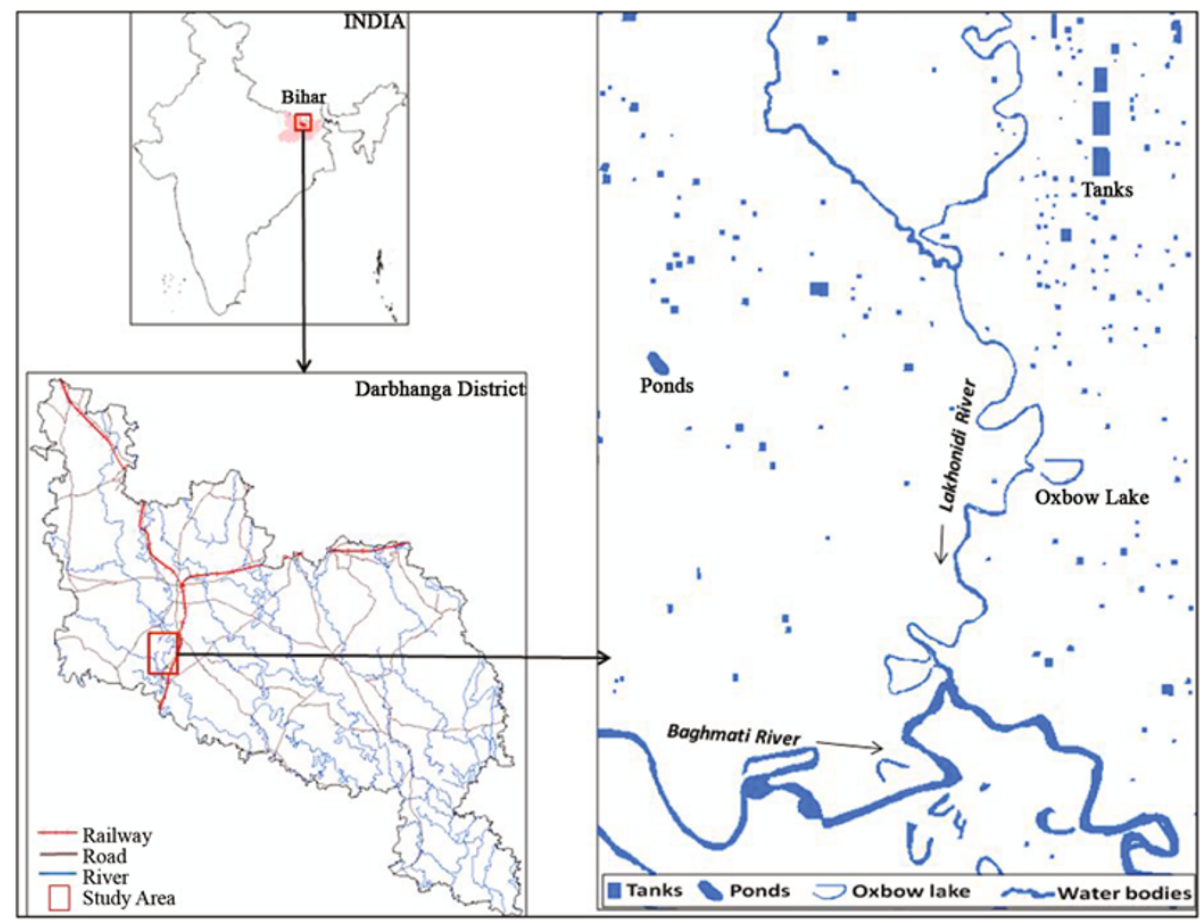

Figure 1. Location of the study area 
Table 1. Satellite data used for the study

\begin{tabular}{lllcrr}
\hline Satellite/Sensor/Orbit & Date of Pass & Polarization/Beam Mode & Incidence Angle & Spatial Resolution(m) & Swath (km) \\
\hline RADARSAT-2/ScanSAR/Ascending & 19 July 2011 & HH and HV/Ascending & $20^{\circ}-49^{\circ}$ & 50 & 500 \\
RADARSAT-2/ScanSAR/Ascending & 22 August 2011 & HH and HV/Ascending & $20^{\circ}-49^{\circ}$ & 50 & 500 \\
RADARSAT-2/ScanSAR/Descending & 15 October 2011 & Fine Quad Pol/Fine (FQ31) & $48^{\circ}-49^{\circ}$ & -2.0 & 23.5 \\
Resourcesat-1/IRS-P6/LISS-III & 12 October 2011 & - & - & 0.5 & 141 \\
DC image & 28 October 2009 & - & - & 4 \\
\hline
\end{tabular}

\section{Methodology}

For the study of backscatter profiles and classification of flood water, the SAR images are calibrated, processed, and geometrically rectified. Twenty-one regions of interest (ROIs) on land and water are taken to evaluate the mean backscatter response in different polarizations (Figure 2). The details of the procedure is explained below and shown in Figure 3.

\subsection{Processing of SAR Data}

Calibration is essential for quantitative analysis because SAR data could be acquired from different sensors or from the same sensor but at different times. SAR is a coherent imaging technology that records both the amplitude and the phase of the backscattered radiation. They have an inherent granular noise called speckle, which degrades the quality of the image and makes interpretation and classification more difficult. In the pre-processing step, SAR images are radiometricaly calibrated and then filtered to suppress speckle. In this study, a $3 \times 3$ Gamma Maximum A Posteriori (MAP) filter is applied on the raw image as it has higher speckle-smoothing capabilities than Frost and Lee-Sigma (Xiao, Li, and Moody 2003). The filtered images are converted into Sigma nought images in decibel $(\mathrm{dB})$ using the formula below:

$$
\begin{aligned}
\operatorname{SIGMA}_{i j}= & 10.0 \times \log _{10}\left(\left(\mathrm{DN} \times \mathrm{DN}+\mathrm{A}_{0}\right) / \mathrm{A}_{j}\right)+10.0 \\
& \times \log _{10}\left(\sin \left(\mathrm{I}_{j}\right)\right)
\end{aligned}
$$

where SIGMA $_{\mathrm{ij}}$ is the output backscatter coefficient in decibels for scan line $i$, pixel $j ; \log _{10}()$ is the logarithm base 10 function; $\mathrm{DN}$ is the input image value for scan line $i$, pixel $j ; \mathrm{A}_{0}$ is the gain offset from the first member of $\mathrm{A}_{0} \mathrm{SEG} ; \mathrm{A}_{j}$ is the expanded gain scaling table value for column $j$; $\sin ($ ) is the sine trigonometric function and; $I_{j}$ is the expanded incident angle table value for column $j$.

All the sigma nought images for each polarization are stacked into a single image. For positional accuracy the images are geometrically co-registered with a master image in Lambert Conformal Conic projection and with Modified Everest as Spheroid.

\subsection{Study of Backscatter Response and Classification of Flood Water}

Twenty-one ROIs (4 in river, 3 in tanks, 3 in land-water section, 7 in flood waters, 3 in partially submerged features, and 1 in oxbow lake) spatially distributed at near range and far range within the study area are selected. The ROIs are selected in order to evaluate the radar backscatter pattern of different water bodies as well as the land water demarcation in different polarizations. Transect lines are drawn within each ROIs to study the behavior of backscatter response of water bodies in different polarization in near range and far range. An average backscatter range is chosen for different water features. From the mean backscatter response study, optimum backscatter threshold ranges are finalized for different water bodies in different polarizations. Further, the average radar backscatter signatures of flood water in near and far

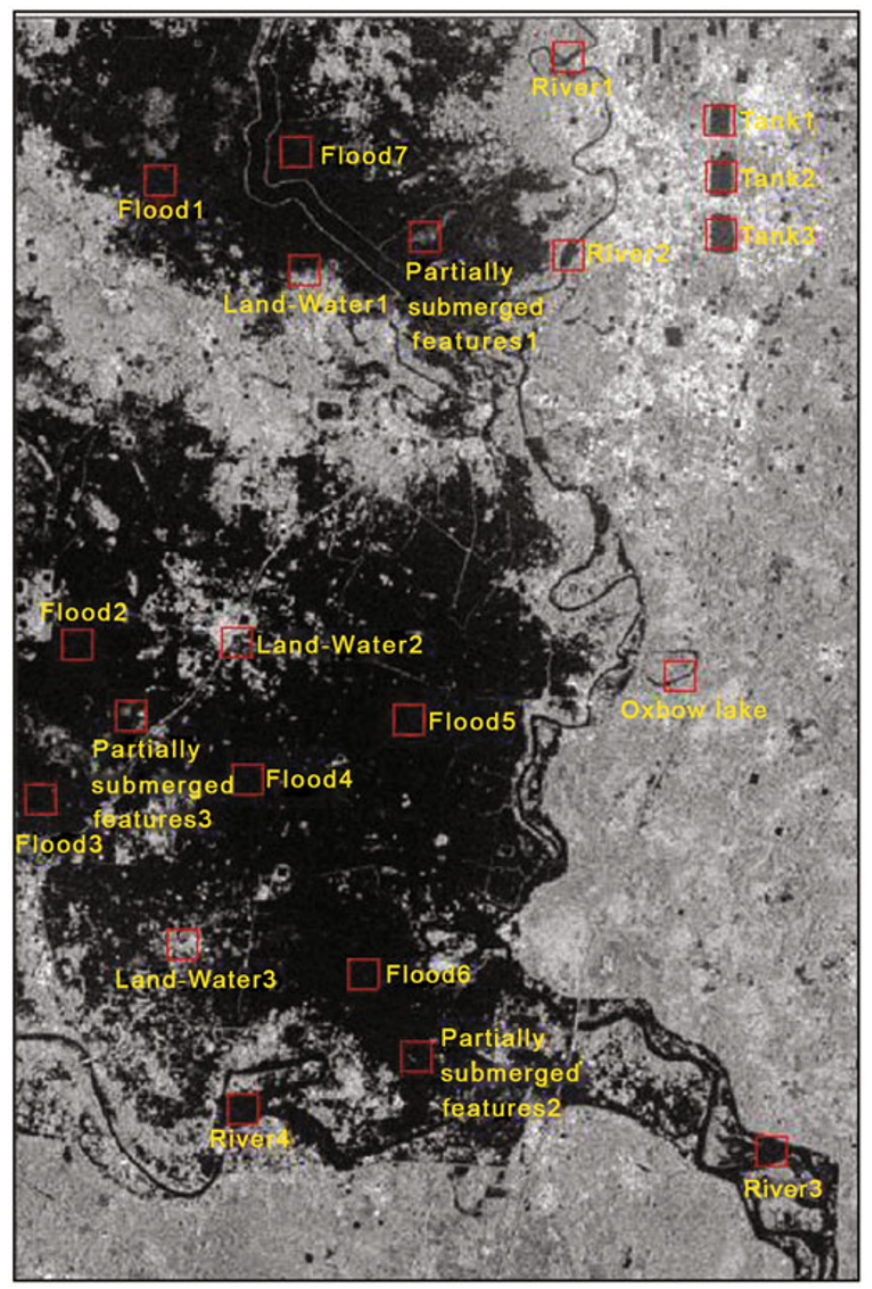

Figure 2. Study area showing regions of interest (ROIs) 


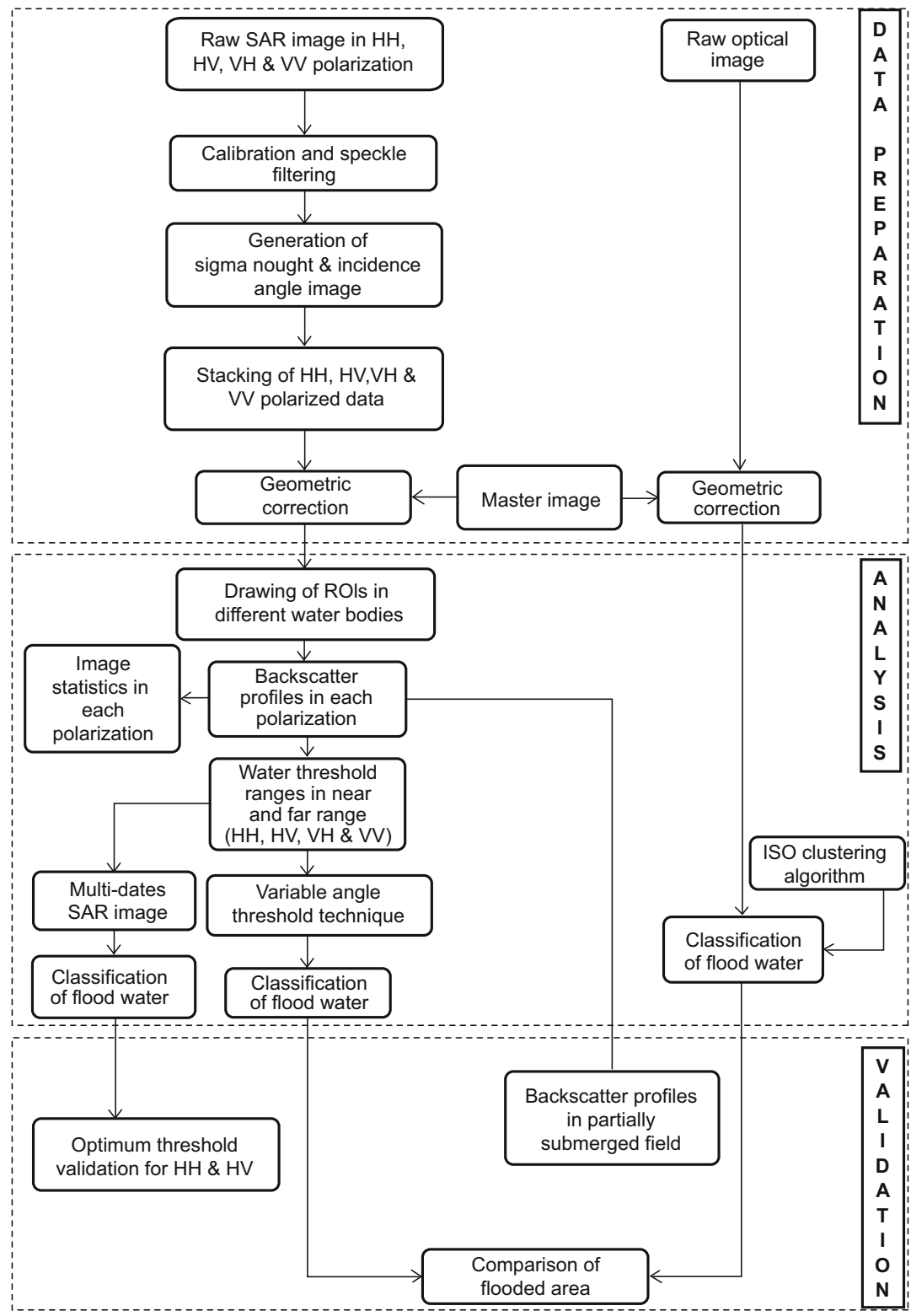

Figure 3. Outline of the methodology

ranges is taken for flood water classification using variable incidence angle threshold technique. Variable incidence angle threshold technique is based on the principle that the radar backscatter from a feature decreases with increase in its incidence angle (Ulaby and Dobson 1989; Baghdadi et al. 2001). Using the threshold ranges derived from the analysis, flood water is classified and the area obtained is compared with the flooded area derived from the optical data.

\subsection{Validation of Optimum Threshold}

The optimum threshold ranges derived from the average radar backscatter signatures from different water bodies in different polarizations are validated using RADARSAT-2 data of 19 July 2011 and 22 August 2011 in HH and HV polarizations.

\section{Results and Discussion}

The results from the study of mean backscatter response, classification of flood water, and optimum threshold values are discussed below.

\subsection{Backscatter of Water Bodies in Multi-Polarizations}

Twenty-one ROIs are taken from the 15 October 2011 SAR image for studying the behavior of radar backscatter signatures in different water bodies. The backscatter response in multi-polarizations is evaluated by drawing the transect lines at various river cross sections and flood pockets in near and far ranges. An average backscatter range is chosen for different water features. From the spectral profiles the average 
backscatter response from all the flood waters ROIs is calculated and it is observed that the response of water in $\mathrm{HV}$ and $\mathrm{VH}$ is similar and the backscatter is in the range of -15 to $-24 \mathrm{~dB}$ (Figure $4 \mathrm{a}$ and $4 \mathrm{~b}$ ). To confirm the similar response of backscattering in $\mathrm{HV}$ and $\mathrm{VH}$, we examined the minimum and maximum backscatter values for other water bodies as well (Figure 5). It is observed that in other water bodies the backscatter signature also behaves the same in $\mathrm{HV}$ and $\mathrm{VH}$ polarizations. Therefore only $\mathrm{HV}$ polarization is used for subsequent analysis.

The backscatter signature range of flood water, river water, tank water, and oxbow lake are shown in Table 2 and the spectral profiles are shown in Figure 5. The dynamic change of the backscatter of flood water is in the higher range when

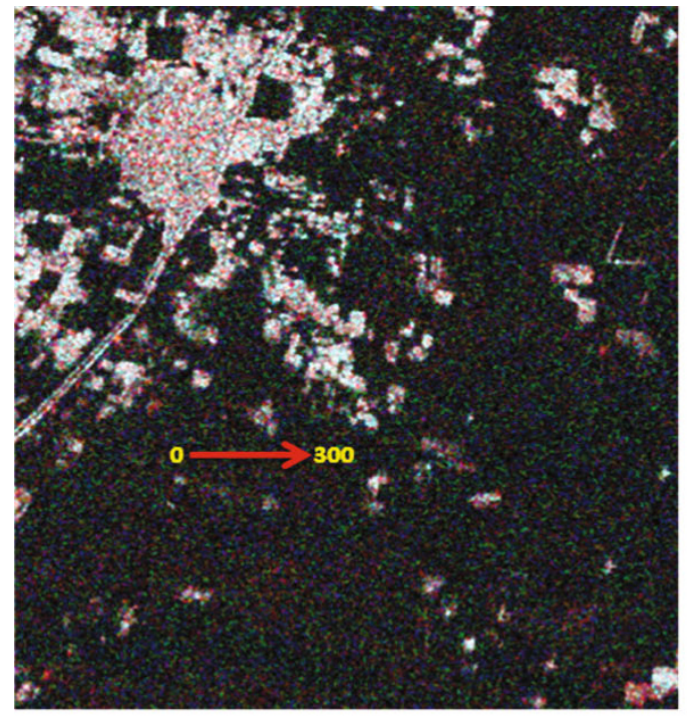

(a)

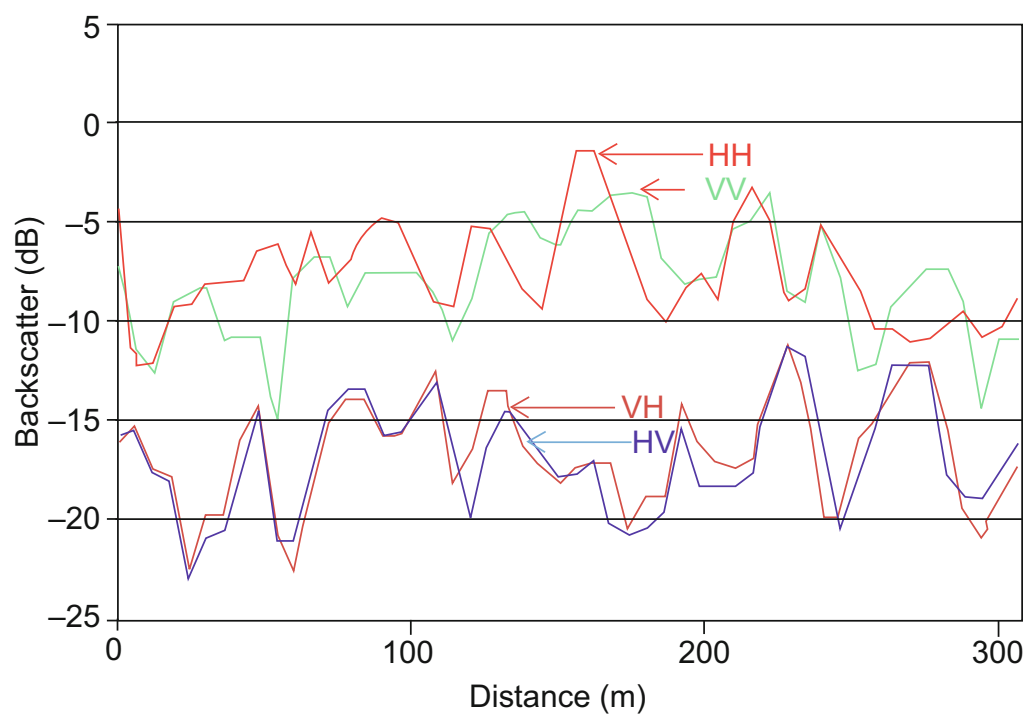

(b)

Figure 4. Transect line drawn in flood water (a); Signature profiles for the flood water in HH, HV, VH, and VV polarizations (b)

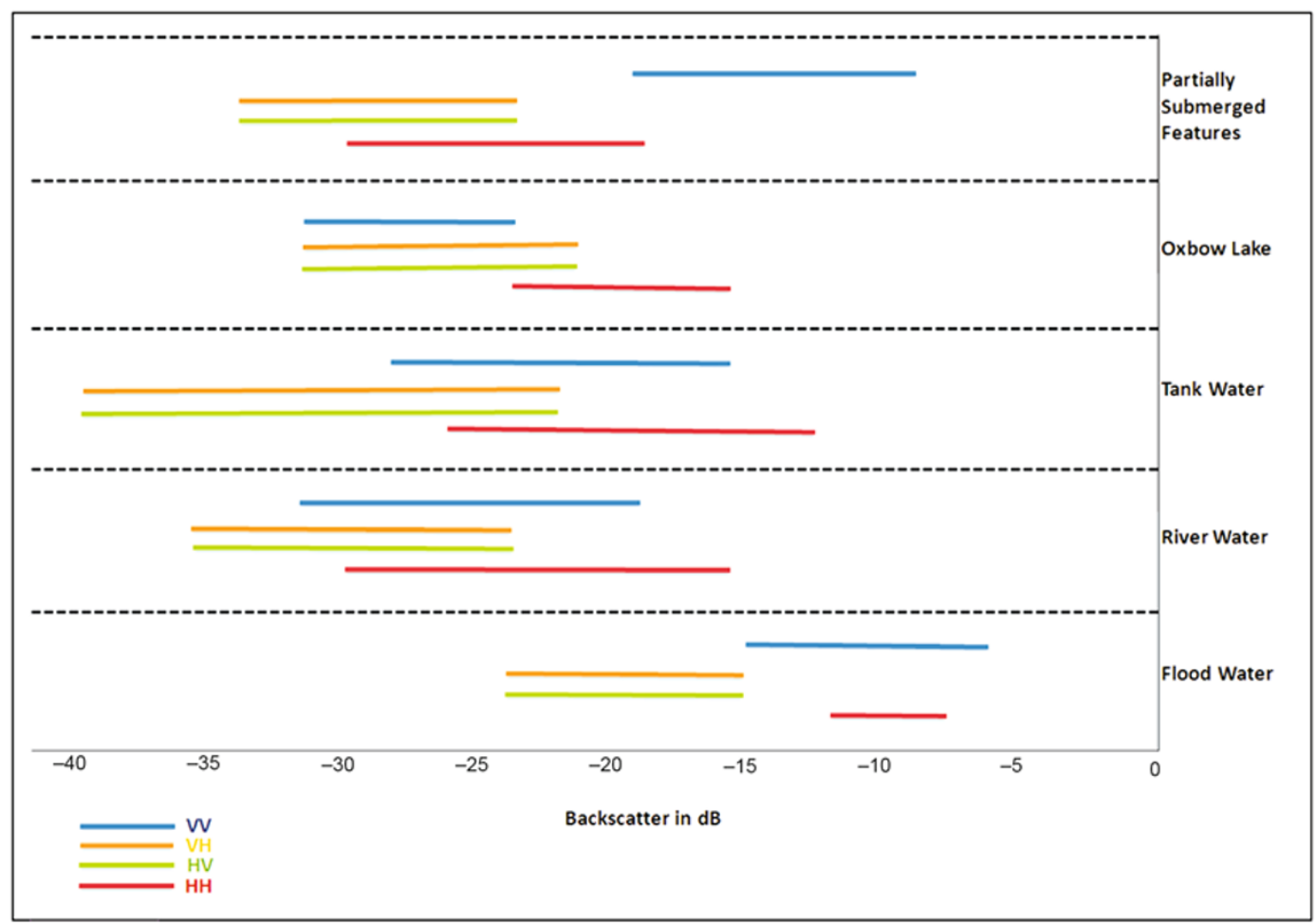

Figure 5. Signature profiles of water bodies in multi-polarizations 
Table 2. Average backscatter (dB) in different water features

\begin{tabular}{lrrrr}
\hline \multirow{2}{*}{ Water Features } & \multicolumn{5}{c}{ Backscatter (dB) } \\
\cline { 2 - 5 } & \multicolumn{1}{c}{ HH } & HV & VH & \multicolumn{1}{c}{ VV } \\
\hline Flood Water & -8 to -12 & -15 to -24 & -15 to -24 & -6 to -15 \\
River Water & -16 to -30 & -24 to -36 & -24 to -36 & -19 to -32 \\
Tank Water & -13 to -26 & -22 to -40 & -22 to -40 & -16 to -28 \\
Oxbow Lake & -16 to -24 & -21 to -32 & -21 to -32 & -24 to -32 \\
Partially Submerged & -18 to -30 & -24 to -34 & -24 to -34 & -8 to -18 \\
$\quad$ & & & & \\
\hline
\end{tabular}

compared to other water bodies in all the polarizations. While $\mathrm{HH}$ is in the range of -8 to $-12 \mathrm{~dB}, \mathrm{VV}$ response is in the range of -6 to $-15 \mathrm{~dB}$, and $\mathrm{HV}$ is in the range of -15 to $-24 \mathrm{~dB}$ (Figure $4 \mathrm{~b}$ ). Unlike for flood water, backscatter for other water bodies is low, which may be because of the calmer water surfaces in the case of tank, river, and oxbow lake. There is a demarcation in the backscatter between flood water and other water bodies in all the polarizations. Through the investigation of radar backscatter of different water bodies it is concluded that there is a clear distinction between radar backscatter characteristics of flood water and other water bodies.

A radiometric profile across the flooded area clearly shows that the $\mathrm{HH}$ polarized signal is less scattered by open water than HV or VV (Figure 6). In the graph the rise represents backscatter response of land features whereas the dip indicates backscatter of the water bodies. This difference shows a clear demarcation between land and water. These observations are in accordance with the results from a number of earlier studies, which suggest that $\mathrm{HH}$ polarization is more useful than VV polarization in distinguishing flooded from non-flooded areas (Hess et al. 1995; Bourgeau-Chavez et al. 2001; Townsend and Foster 2002).

The submerged fields' mean backscatter ranges between -18 to $-30 \mathrm{~dB}$ in $\mathrm{HH}$ polarization, while in HV polarization it ranges between -24 to $-34 \mathrm{~dB}$ and in $\mathrm{VV}$ polarization it ranges between -8 to $-18 \mathrm{~dB}$. Further by making a composite of $\mathrm{HH}, \mathrm{HV}$, and $\mathrm{VV}$ polarizations (Figure 7) and assigning Red to HH polarization, Green to HV polarization, and Blue to $\mathrm{VV}$ polarization, features such as built-up area (seen in red color) and partially submerged features (seen in blue color) are very distinct. VV has shown significant changes (in blue) at three places (the encircled areas 1, 2, and 3 in Figure 7), which were found to be cropped fields. Submerged features identified in color composite are compared with pre-flood DC

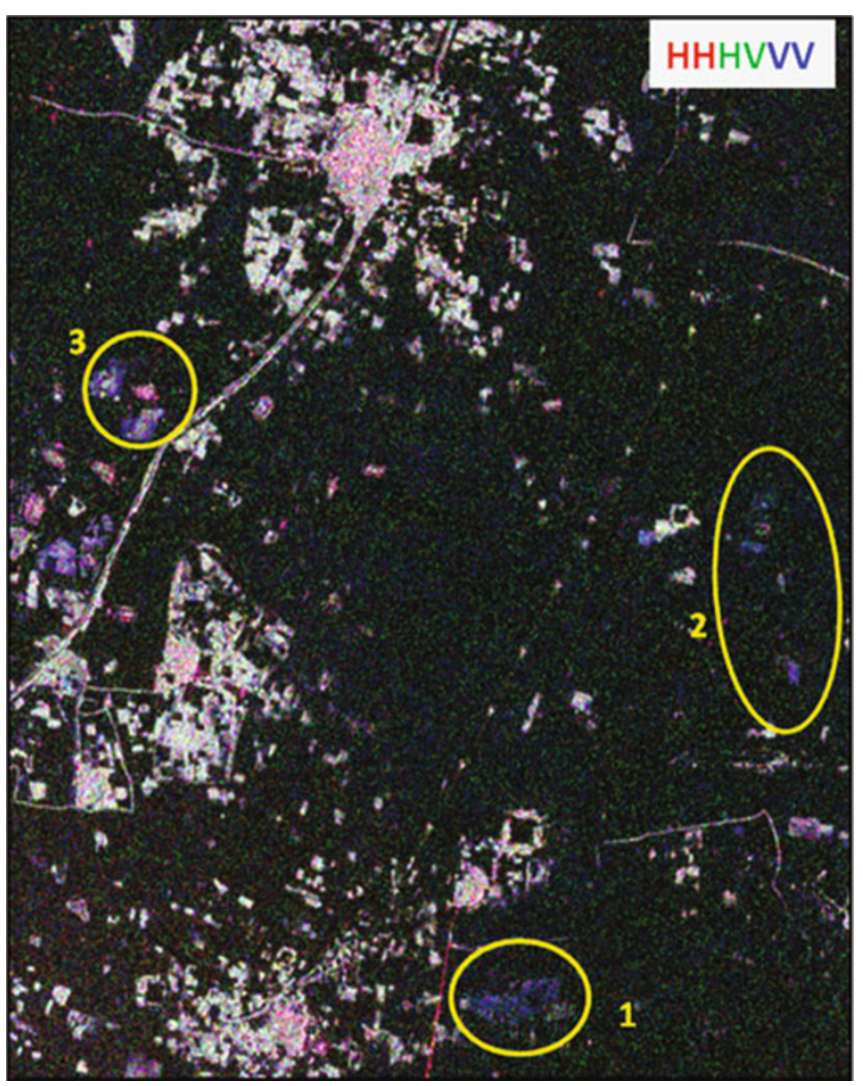

Figure 7. $\mathrm{HH}, \mathrm{HV}$, and VV polarized image in RGB combination. Areas 1, 2, and 3 are submerged agricultural fields
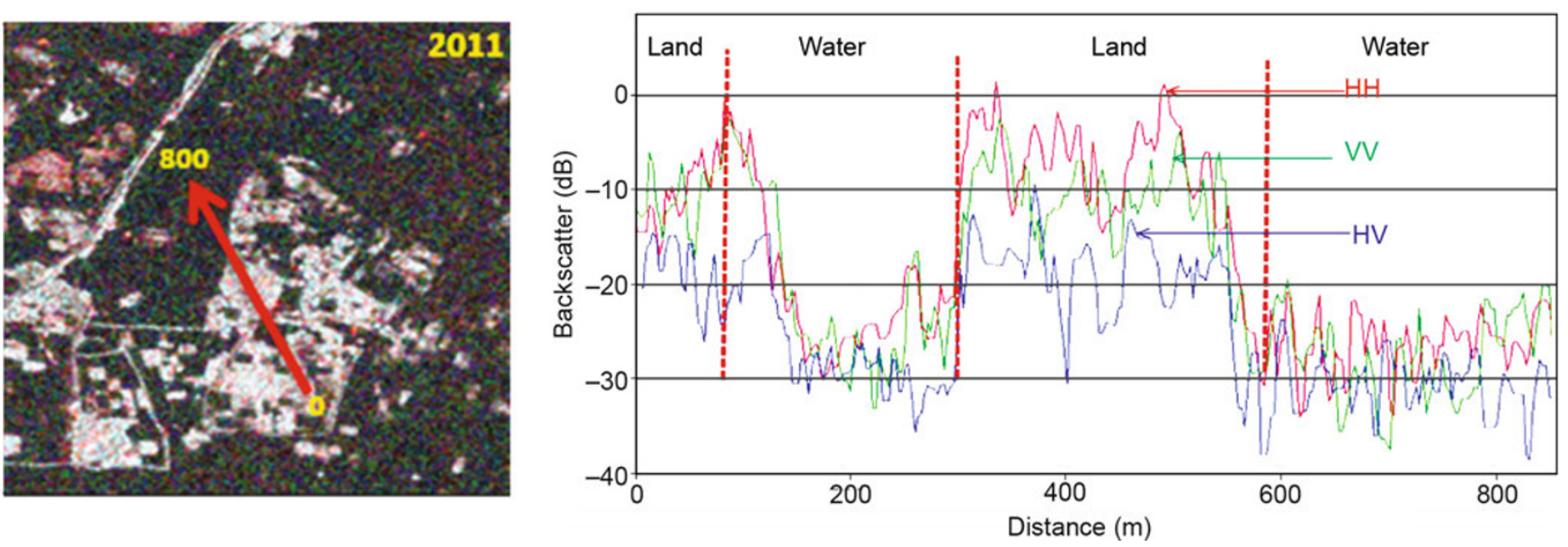

Figure 6. Radiometric profile over land-water demarcation from RGB composition in HH, HV and VV polarizations 
data (Figure 8). Individual spectral profiles are created for the three submerged agricultural fields in different polarizations by drawing a transect line (Figure 8). The backscatter is higher in VV polarization as compared to other polarizations. This shows that VV polarization is more sensitive to surface roughness even in floods. This observation is very helpful for identifying submerged agricultural fields, roads, railways, built-up lands, and so on during floods.

\subsection{Flood Water Classification Using Radar Backscatter in Multi-Polarizations}

The mean backscatter values derived from the study of flood water in the near and far ranges varies between -8 to $-12 \mathrm{~dB}$ in $\mathrm{HH}$ polarization, -15 to $-24 \mathrm{~dB}$ in $\mathrm{HV}$ polarization, and -6 to $-15 \mathrm{~dB}$ in $\mathrm{VV}$ polarization. This suggests that if the same threshold range is used for all the polarizations it can

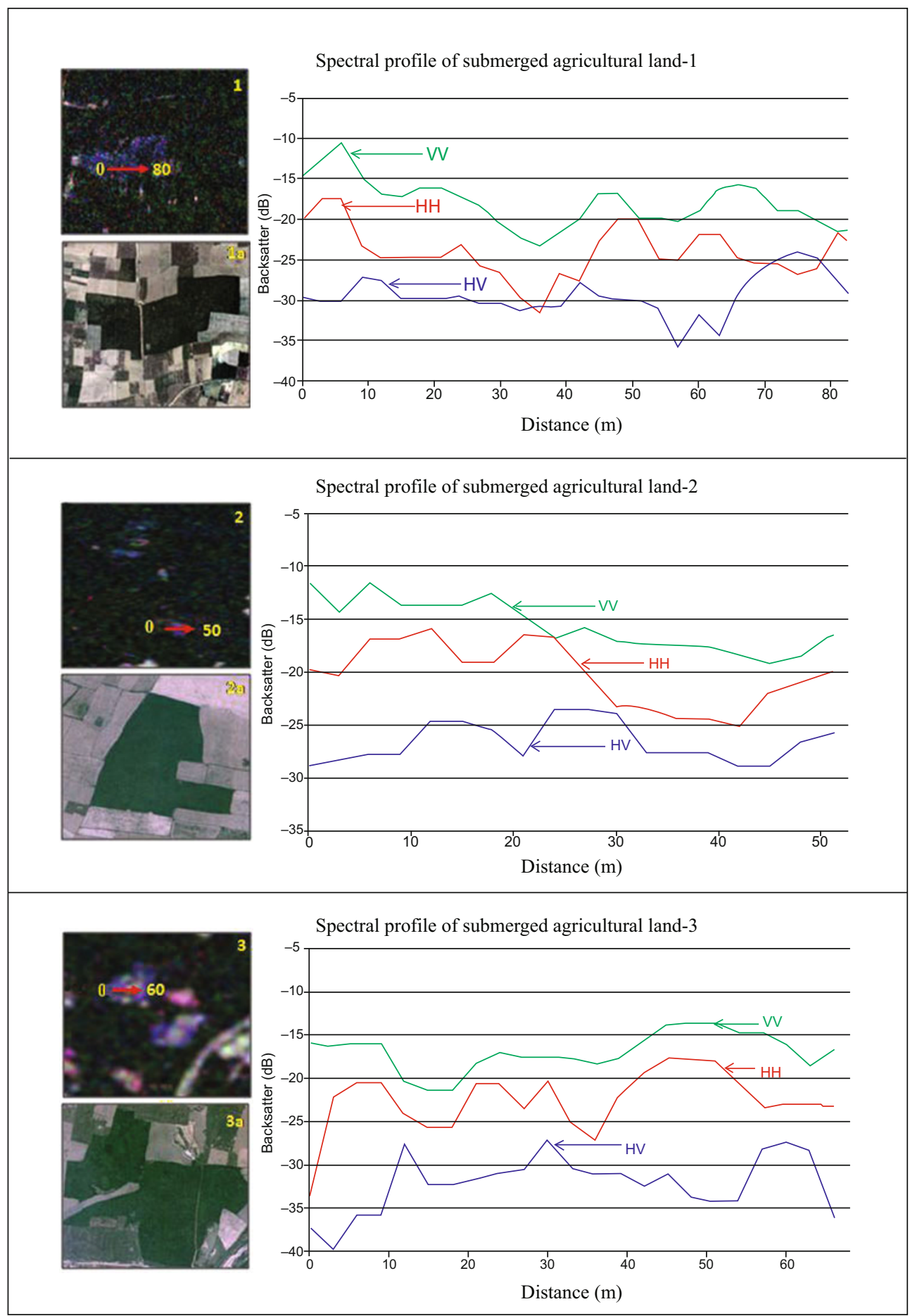

Figure 8. Spectral profiles for submerged agricultural fields in $\mathrm{HH}, \mathrm{HV}$, and VV polarizations. 1, 2, and 3 are composite SAR images, and $1 \mathrm{a}, 2 \mathrm{a}$, and $3 \mathrm{a}$ are the corresponding pre-flood DC optical image 
either overestimate or underestimate the flooded area. The polarization-specific backscatter values enable improved classification of flood water. By using these threshold ranges, the 15 October 2011 SAR image is classified. The classified flood water layers are cross checked with the respective polarized image by swiping. The SAR images (left) and corresponding water layers (right) in different polarizations are shown in Figure 9. Table 3 shows the thresholds and the flood inundation statistics derived using the thresholds.

The total flooded area in the HH polarization is 401 ha, whereas in the HV polarization it is estimated at 371 ha. In the VV polarization, the flooded area is 326 ha. In $\mathrm{HH}$ polarization the area classified as flooded is the largest when compared to others. There is a difference in the flooded area discrimination depending on the polarizations. Visual comparison between the SAR images and the corresponding classified water layers shows that in $\mathrm{HH}$ polarization flood
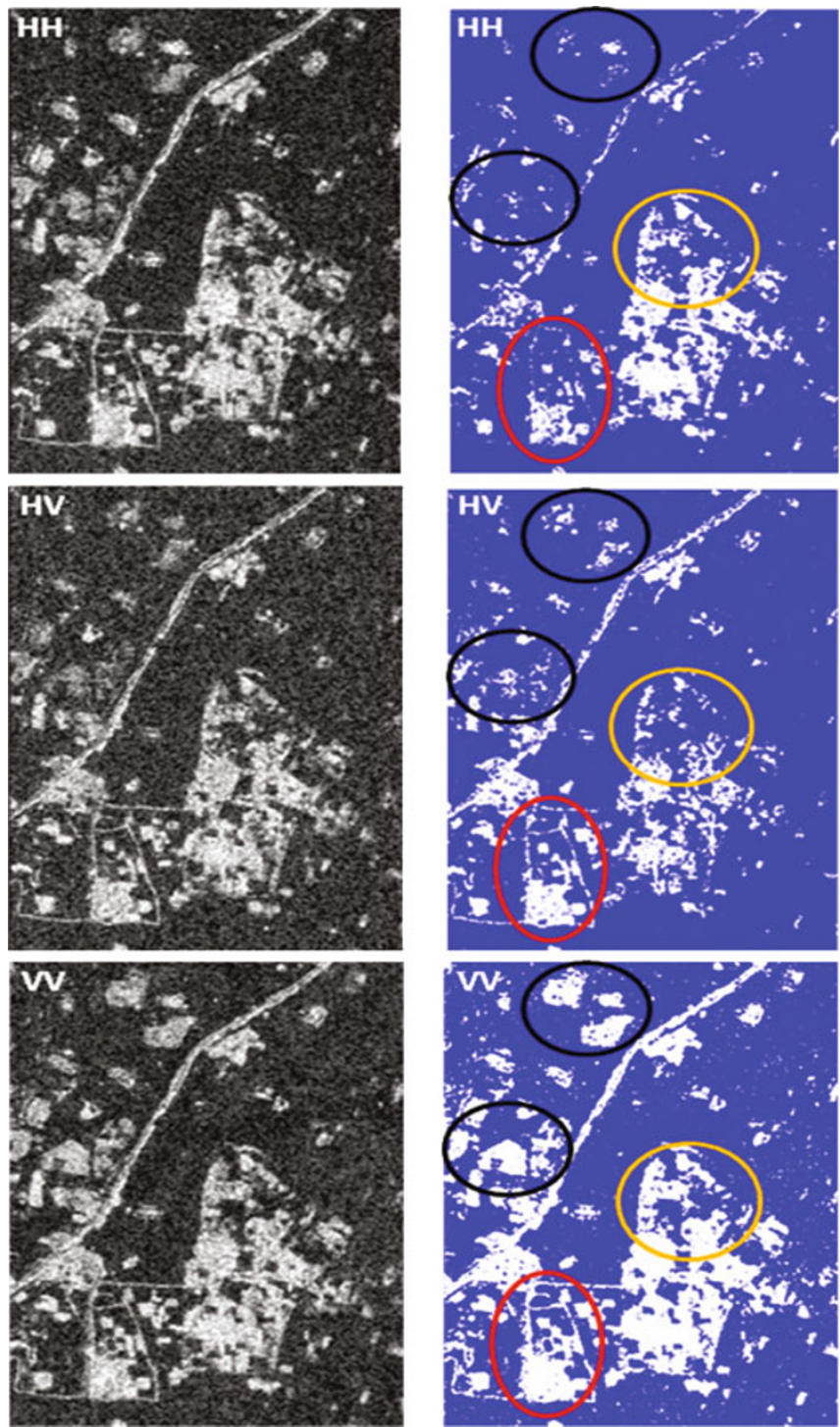

Figure 9. Flood water classified in $\mathrm{HH}, \mathrm{HV}$, and VV polarizations
Table 3. Thresholds and statistics for classified flood water areas

\begin{tabular}{lccc}
\hline Polarization & Threshold (dB) & No. of Flooded Pixel & Area (ha) \\
\hline HH & -8 to -12 & 445,792 & 401.2 \\
HV & -15 to -24 & 411,716 & 370.5 \\
VV & -6 to -15 & 362,444 & 326.1 \\
\hline
\end{tabular}

water is classified very well as compared to other polarizations. Some flooded areas are better classified in HV polarization, while in $\mathrm{HH}$ and $\mathrm{VV}$ polarizations they are classified incorrectly. The red circle in Figure 9 shows that the flood water is better classified in $\mathrm{HH}$ polarization as compared to $\mathrm{HV}$ and VV polarizations. The orange circle in the figure shows that HV has classified the flooded pixel where $\mathrm{HH}$ is unable to identify. The black circles indicate the potential of VV polarization in identifying the partially submerged fields. This study shows that $\mathrm{HH}$ polarization is good in demarcating land and water. VV polarization has the potential to identify partially submerged features, which can be helpful for flood damage assessment.

\subsection{Verification of the Classification Result}

Resourcesat-1 LISS-III image of 12 October 2011 is classified for flood water and the inundation statistics are compared with that obtained from classifying the SAR data. For the classification of optical data, unsupervised iterative ISODATA clustering algorithm is used with a convergence threshold of 0.95 , maximum iterations of 10 , and 20 spectral clusters. Distinguished classes are grouped from the classification output and final flood layer is delineated. The total flooded area identified in the optical image is 390 ha. The total flood area in $\mathrm{HH}, \mathrm{HV}$, and VV combined is 407 ha (Table 4). The total flooded area in the combined flood water layer is in accordance with the LISS-III derived flood area. Figure 10 shows the comparison of flood extent in multi-polarized data and optical data.

\subsection{Validation of the Optimum Threshold for Flood Water Classification}

Using the threshold ranges (Table 2) from the study of mean backscatter profiles in the fine beam quad polarization data, other multi-dates SAR images are classified in an attempt to validate these threshold ranges. In order to optimize the threshold ranges this exercise is carried out in $\mathrm{HH}$ and $\mathrm{HV}$

Table 4. Comparison of flooded areas in optical data and SAR (HH, HV, VV combined) data

\begin{tabular}{llcc}
\hline Date & Satellite/Sensor & $\begin{array}{c}\text { No. of Flooded } \\
\text { Pixels }\end{array}$ & $\begin{array}{c}\text { Area } \\
\text { (ha) }\end{array}$ \\
\hline 12 October 2011 & Resourcesat-1/LISS-III & 6788 & 390 \\
15 October 2011 & RADARSAT/SAR (Combined) & 452,981 & 407 \\
\hline
\end{tabular}



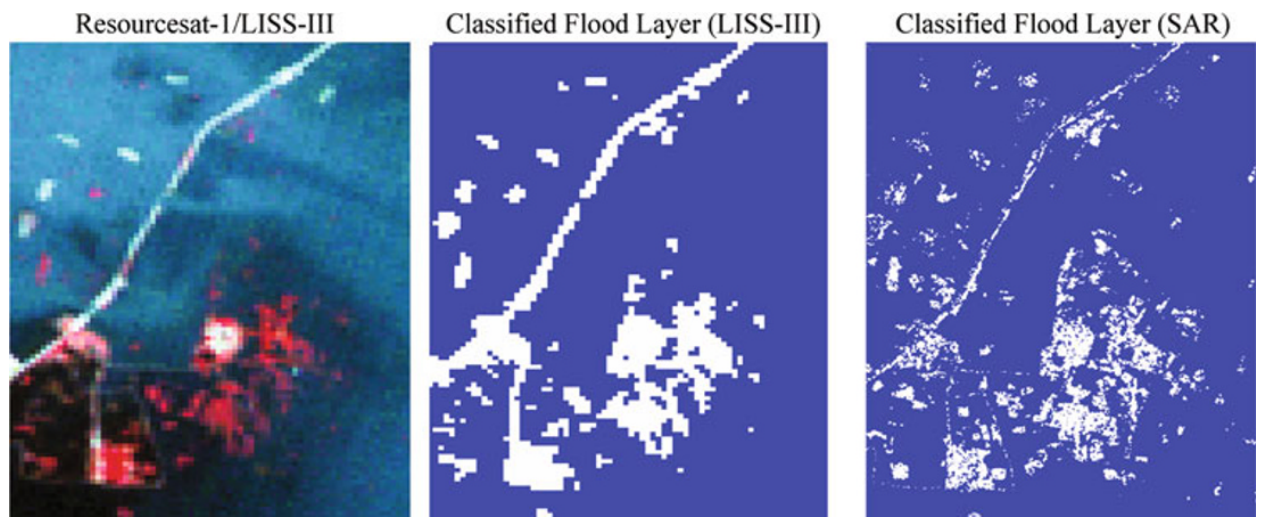

Figure 10. Flood areas identified with optical data and SAR (HH, HV, and VV combined) data

polarized dataset. Figure 11 shows the results of flood water classification using the backscatter range of -8 to $-12 \mathrm{~dB}$ in $\mathrm{HH}$ polarization and -15 to $-24 \mathrm{~dB}$ in $\mathrm{HV}$ polarization on two sets of SAR images in HH and HV polarizations. The above mentioned threshold ranges produced good results, which is confirmed by overlaying the corresponding SAR data. These results indicate that the threshold ranges derived from this study can be used for automated classification of flood water in the specified incidence angle image $\left(20^{\circ}-49^{\circ}\right)$. Due to the non-availability of VV polarized dataset, the classification is done for $\mathrm{HH}$ and $\mathrm{HV}$ polarizations only. In a disaster situation, determining threshold values for flooded area delineation using SAR images takes away very valuable time for prompt emergency response. Optimum thresholds determined beforehand, such as those derived from this study, can be directly used and help speed up flood disaster response.

\section{Conclusion}

From this study optimum threshold ranges for the delineation of flood water using higher incidence angle SAR images $\left(20^{\circ}\right.$ to $49^{\circ}$ ) is derived for $\mathrm{HH}, \mathrm{VV}$, and $\mathrm{HV}$ polarizations. In $\mathrm{HH}$ polarization the threshold varies from -8 to $-12 \mathrm{~dB}$, whereas in $\mathrm{HV}$ and $\mathrm{VH}$ polarizations it varies from -15 to $-24 \mathrm{~dB}$, and in VV polarization it varies from -6 to $-15 \mathrm{~dB}$. The optimum threshold ranges can be used for rapid flood water classification. HH polarization has better potential to differentiate flood water. However, by combining the flood layers derived from $\mathrm{HH}, \mathrm{HV}$, and VV polarizations the flood inundation area obtained matches closely to the classification results of optical data. Backscatter response from $\mathrm{HV}$ and $\mathrm{VH}$ is the same and either $\mathrm{HV}$ or $\mathrm{VH}$ cross polarization is adequate for mapping floods. This study also revealed that in multi-polarized

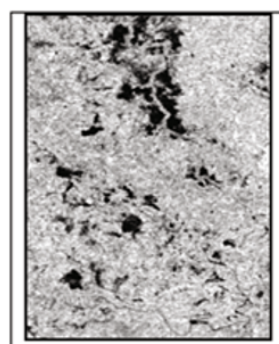

HH Polarization 19 July 2011

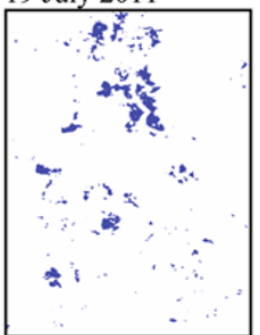

Classified flood

layer

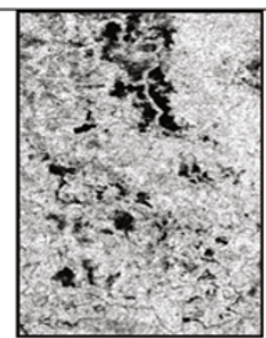

HV Polarization 19 July 2011

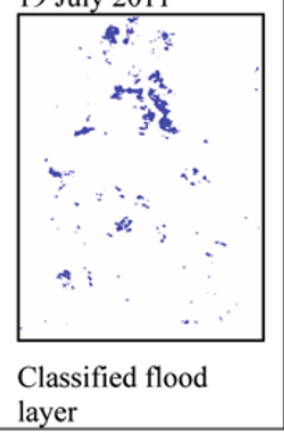

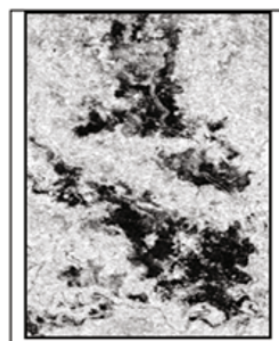

HH Polarization 22 August 2011

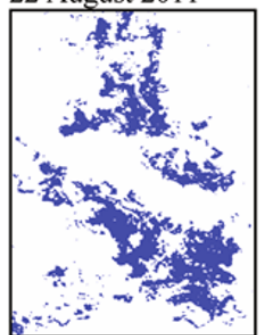

Classified flood layer

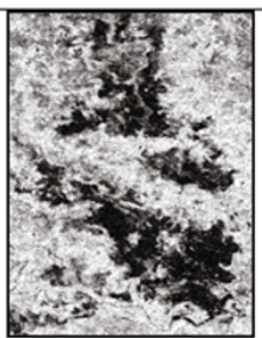

HV Polarization 22 August 2011

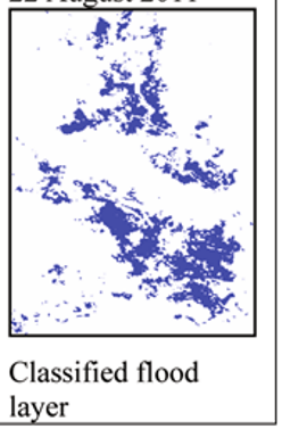

Figure 11. Multi-dates $\mathrm{HH}$ and HV polarized image classification using threshold ranges for flood water classification 
data VV polarization has the potential to identify partially submerged features, confirming that VV polarization is sensitive to roughness of the surface. The optimum threshold ranges can be applied to SAR data received during flood disasters for classification of flood inundation area and generating flood maps. This can help in expediting the flood mapping process and timely dissemination of flood maps to the concerned disaster response agencies.

\section{Acknowledgments}

The authors gratefully acknowledge the support and guidance provided by the Director, National Remote Sensing Centre, Hyderabad and the Deputy Director, Remote Sensing Applications Area, National Remote Sensing Centre, Hyderabad.

\section{References}

Baghdadi, N., M. Bernier, R. Gauthier, and I. Neeson. 2001. Evaluation of C-Band SAR Data for Wetlands Mapping. International Journal of Remote Sensing 22 (1): 71-88.

Bourgeau-Chavez, L. L., E. S. Kasischke, S. M. Brunzell, J. P. Mudd, K. B. Smith, and A. L. Frick. 2001. Analysis of Space-Borne SAR
Data for Wetland Mapping in Virginia Riparian Ecosystems. International Journal of Remote Sensing 22 (18): 3665-87.

Campbell, J. B. 2002. Introduction to Remote Sensing. New York: Guilford.

Di Baldassarre, G., G. Schumann, L. Brandimarte, and P. Bates. 2001. Timely Low Resolution SAR Imagery to Support Floodplain Modeling: A Case Study Review. Survey in Geophysics 32 (3): 255-69.

Hess, L. L., J. M. Melack, S. Filoso, and Y. Wang. 1995. Delineation of Inundated Area and Vegetation along the Amazon Floodplain with the SIR-C Synthetic-Aperture Radar. IEEE Transactions on Geoscience and Remote Sensing 33 (4): 896-904.

Horritt, M. S., D. C. Mason, and A. J. Luckman. 2001. Flood Boundary Delineation from Synthetic Aperture Radar Imagery Using a Statistical Active Contour Model. International Journal of Remote Sensing 22 (13): 2489-507.

Xiao, J. F., J. Li, and A. Moody. 2003. A Detail-Preserving and Flexible Adaptive Filter for Speckle Suppression in SAR Imagery. International Journal of Remote Sensing 24 (12): 2451-65.

Smith, L. C. 1997. Satellite Remote Sensing of River Inundation Area, Stage, and Discharge: A Review. Hydrological Processes 11 (10): 1427-39.

Townsend, P. A., and J. R. Foster. 2002. A Synthetic Aperture RadarBased Model to Assess Historical Changes in Lowland Floodplain Hydroperiod. Water Resources Research 38 (7): 1115-25.

Ulaby, F. T., R. K. Moore, and A. K. Fung. 1986. Microwave Remote Sensing Active and Passive, Vol. II: Radar Remote Sensing and Surface Scattering and Emission Theory. Dedham, MA: Artech House.

Ulaby, F. T, and M. C. Dobson. 1989. Handbook of Radar Scattering Statistics for Terrain. Norwood, MA: Artech House.

Open Access This article is distributed under the terms of the Creative Commons Attribution License which permits any use, distribution, and reproduction in any medium, provided the original author(s) and source are credited. 